OPEN ACCESS

Edited by:

Bonita London,

Stony Brook University, United States

Reviewed by:

Jon Mason,

Charles Darwin University, Australia

Jiyun Elizabeth Shin,

Binghamton University, United States

${ }^{*}$ Correspondence:

Rebecca Beals

rebecca.beals@unco.edu

Specialty section:

This article was submitted to

STEM Education,

a section of the journa

Frontiers in Education

Received: 15 February 2021

Accepted: 16 August 2021

Published: 03 September 2021

Citation:

Beals R, Zimny S, Lyons F and Bobbitt O (2021) Activating Social

Capital: How Peer and Socio-

Emotional Mentoring Facilitate Resilience and Success for Community

College Students.

Front. Educ. 6:667869.

doi: 10.3389/feduc.2021.667869

\section{Activating Social Capital: How Peer and Socio-Emotional Mentoring Facilitate Resilience and Success for Community College Students}

\author{
Rebecca Beals ${ }^{1,2 *}$, Sean Zimny ${ }^{1}$, Faith Lyons ${ }^{1}$ and Olivia Bobbitt ${ }^{1}$ \\ ${ }^{1}$ Department of Sociology, University of Northern Colorado, Greeley, CO, United States, ${ }^{2}$ Institute for Social Research, University \\ of New Mexico, Albuquerque, NM, United States
}

This article details the impact of the intensive mentoring model, through faculty-to-student and peer-to-peer mentoring, utilized in WAESO-LSAMP community colleges. We pay particular attention to the practice of socio-emotional mentoring, the development of a "mentoring chain," and the impact of communities of support on student and faculty participants. Specifically, we discuss how these separate modes of mentoring impact students from underrepresented students in developing and activating social capital, developing collaborative support systems, fostering confidence and self-efficacy, combatting impostor syndrome and stereotype threat, and embracing the importance of failure in the scientific process. Methods and data include qualitative analysis of forty-six in-depth interviews with program participants, including faculty mentors and community college students, at three community college sites within the WAESO-LSAMP alliance. We address specific implications for faculty working with underrepresented STEM community college students and provide evidence of best practices for setting up a community of support that leads to academic and personal success.

Keywords: mentoring, peer mentoring, self-efficacy, resilience, social capital, community college, underrepresented students

\section{INTRODUCTION AND LITERATURE REVIEW}

Critical and intentional mentoring impacts students, particularly underrepresented STEM students, including black, indigenous, people of color and also low-income, first generation college students, in important ways, including their identity development (Eagan et al., 2017; Estepp et al., 2017; Malone and Barabino, 2009), self-efficacy (confidence in performing essential parts of their studies) (Chemers et al., 2011; Crisp et al., 2017; Estepp et al., 2017), commitment to STEM education, and long-term success (Crisp et al., 2017; Dika and Martin, 2018; Hurtado et al., 2009). To best address this critical student development, mentoring should strategically develop social and cultural capital, provide diverse communities of mutual support, and intentionally facilitate the development of self-efficacy and resilience (Banda and Flowers, 2017; Beals 2019; Hurtado et al., 2009; Hurtado et al., 2015; Revelo and Baber, 2018). Critical mentoring has the ability to impact attraction and recruitment of underrepresented students to STEM as well as support their retention, progression, and long-term success in various STEM environments (Hurtado et al., 2009; Dika and Martin, 2018; Monarrez et al., 2019).

Furthermore, critical mentoring is important for promoting and supporting diverse networks amongst underrepresented STEM students. Research programs for underrepresented students like 
the Louis Stokes Access to Minority Participation (LSAMP) that incorporate intensive mentoring are necessary to increase diversity in the workforce, particularly in biomedical and science fields (Fuchs et al., 2016). Beyond the broad goals of increasing and supporting diversity, LSAMP intensive mentoring environments facilitate faculty-led undergraduate research experiences that have a multitude of positive academic and social outcomes (Kim and Sax, 2009). Intensive LSAMP mentoring can lead to increased self-efficacy and confidence in working with esteemed faculty, both of which are important as underrepresented students often feel uncomfortable reaching out to faculty for support (Schwartza et al., 2016) in college due to fears of being seen as incompetent or like they do not belong (Baker, 2013).

The remainder of this article will detail the way that intensive mentoring takes place and impacts underrepresented students in STEM fields. Particular attention is paid to the important role of social capital (Baker, 2013; Mondisa, 2020; Schwartza et al., 2016) and how students effectively develop strong networks of support and camaraderie that are essential to their growth and success (Mondisa and McComb, 2015). We discuss how the development of "mentoring chains" strong, authentic, and diverse communities of mentors - influences the diverse forms of support given by different members within the community. We discuss the role of various community members in helping foster confidence which leads to self-efficacy (Estrada et al., 2018; Fuchs et al., 2016; Starobin et al., 2016), and resilience through nontechnical training (Hochanadel and Finamore, 2015) facilitated by both peer and faculty support. This ultimately leads to a community where students feel supported, like they belong, and have the necessary tools and social capital to be successful, and the confidence and problem solving abilities to be resilient in the face of challenges (Hochanadel and Finamore, 2015).

\section{ACTIVATING SOCIAL CAPITAL}

Social capital theory is useful for identifying the key strategies of effective mentoring relationships, especially for underrepresented students (Mondisa, 2020; Hezlett and Gibson, 2007). Social capital theory asserts that relationships are essential for providing resources necessary to reach desired goals, especially in higher education (Mondisa, 2020; Hezlett and Gibson, 2007). Mentoring communities are places where this social capital is developed and contributes to the success of underrepresented STEM students (Mondisa and McComb, 2015). The successful development of social capital in STEM is crucial for educational success (Mondisa, 2020). Intentional mentoring strategies are vital for underrepresented students where the development of social capital improves educational outcomes (Saw, 2020). Integrating the development of social capital within the mentoring strategy offers promise to enhance career and organization development (Hezlett and Gibson, 2007). The social capital accrued during student's time in college provides individuals with a starting foundation, "like the first pennies in a child's piggy bank that can be cultivated and support their long- term career and personal goals" (Mondisa and McComb, 2015, pg. 158).

Both the quality and quantity of connections that underrepresented students make with individuals and organizations on campus determine their likelihood of success (Museus, 2020). It is often assumed that social capital is gained by students through their connections to faculty, as faculty often work as gatekeepers to their discipline and to the support networks that provide avenues for obtaining social capital. However, critical mentoring should also include social and cultural connections with other peers in the STEM environment in an effort to develop a shared sense of space and community within spaces that are often seen as exclusionary by underrepresented students. While faculty mentors connect mentees with other sources of campus support, which students can then utilize to expand their network (Museus and Neville, 2012), peer connections and a shared sense of community ultimately embed students within disciplinary environments that they seek to join.

Creating intentional social networks for underrepresented students to meet others not only helps to promote social capital, it also leads to the development of an authentic social community of peers who share similar backgrounds, experiences, goals, and challenges (Museus and Neville, 2012). This social community becomes a source of mutually beneficial, shared development by engaging in "an environment where likeminded individuals engage in dynamic, multidirectional interactions that facilitate social support" (Mondisa and McComb, 2015, pg. 152).

Social capital and access to networks is important for underrepresented students as a result of the hidden curriculum in higher education, where organizational behavior is often structured around middle- and upper-class values (Rist, 1970). When this cultural capital is rewarded, it can lead to students from underrepresented backgrounds feeling isolated and like they do not belong within the academic environment (Rist, 1970). Socialization into these spaces is influenced by peers, social networks, and values. The hidden curriculum of higher education, and STEM fields particularly, leads to unclear expectations tied to racial or class background, and leads to challenges in developing effective strategies of communication, collaboration, and relationship building-all critical for success in STEM education (Jackson et al., 2016; Stanton-Salazar, 2011.) The hidden curriculum ultimately reproduces race and class inequalities in higher education (Royster, 2003) and leads to differential attrition rates by race and social class (Graham, 2019). Faculty are necessary for deconstructing the hidden curriculum (Hansson, 2018) and the development of collaborative skills and effective communication is strongly influenced by peer support and community (Stolle-McAllister, 2011).

Underrepresented students often desire multiple kinds of mentoring relationships and collaborative experiences because having a variety of networks allows students to have different needs addressed by different individuals. This in turn facilitates the development of social capital (Graham, 2019). Having varying types of mentoring relationships across the diverse spaces in academia helps students develop skills that are necessary for 
academic and social engagement and promotes emotional development through socioemotional mentoring. While the engagement with various types of mentoring is useful, if these networks are not embedded within disciplinary environments students risk feeling isolated and like they do not belong within the key space of their academic socialization.

Embedded disciplinary support systems can positively impact the experiences of underrepresented STEM (Jackson et al., 2016). Mentorship helps to foster an environment of belonging and support, personal transformation, and professional development (Afghani et al., 2013). Mentors provide students the academic and social support they need to succeed within their STEM discipline. One study on underrepresented STEM students highlights the significance of mentoring for long-term STEM success (Griffin et al., 2010). Findings indicate the continuing significance of fostering positive mentoring relationships to facilitate student persistence, addressing exclusionary climate and disciplinary environment issues, and the representation and support of faculty of color in STEM fields (Griffin et al., 2010). Engagement with these issues has a positive impact on the development of self-efficacy, a student's commitment to academic goals, and feelings of empowerment to reach desired goals, especially in terms of challenging the impostor phenomenon and fears of failure within a challenging environment (Beals, 2019).

\section{The Importance of Peer Support}

Peer support is also important in developing and activating social capital, especially through the provision of both socio-emotional and academic support, which leads to a more successful integration into campus community and culture for students (Moschetti et al., 2017). Targeted initiatives, such as summer bridge programs, support underrepresented students as they begin to build social and cultural capital. Through connecting peers from similar backgrounds prior to the start of college while facilitating engagement with peers and faculty, Summer Bridge provides access to STEM environments that facilitate meaningful participation in academic activities, which both builds and strengthens student's social and professional networks (StolleMcAllister, 2011).

Peer mentors can act both as guides who share information and as friends who provide psychosocial support, such as normalizing common struggles and decreasing feelings of isolation. Peer mentoring provides support to students as they develop a sense of belonging and facilitates the development of positive science identities (Zaniewski and Reinholz, 2016). Similarly, when important peer groups both value and support STEM learning and environments, these peer supports help to validate sense of belongingness in STEM fields (Leaper, 2014). Peer support also mitigates negative aspects of underrepresented student experiences (Watkins and Mensah, 2019). Institutions can and should provide structures where supportive peer networks can emerge to support underrepresented students in STEM. Peer support also impacts individual's willingness and confidence to pursue STEM careers. STEM peers have been found to influence motivation, which in turn predicts their intent to pursue a STEM career (Robnett, 2012).

\section{Mentoring Chains Community, Confidence, Self-Efficacy, and Social Capital}

The intensive mentoring facilitated through formal academic programs, like LSAMP, allows individuals to share their academic, social, and cultural experiences with themselves, their peers, and faculty mentors (Kendricks et al., 2013). Program facilitated mentoring is primarily conducted through a network of faculty who have a common interest in the student's retention and academic success, and who nurture the student by integrating academic advising into social and professional meetings with students. Students in these programs perceive mentoring as the biggest contributing factor to their academic success (Kendricks et al., 2013).

Broader networks of mentors that include graduate and undergraduate students have been shown to be effective in providing important support for students and scholars. Mentoring triads (post-graduates and faculty each assisting in mentoring undergraduates) provide students with resources and psychosocial support (Aikens et al., 2017). Closed triads, where post-graduates, faculty, and undergraduate students collaboratively communicated with each yielded the best results (Aikens et al., 2017). This evidence may point to a network or chain of mentors yielding the most optimal social support.

Collaborative mentoring chains have also been shown to influence the development of a strong academic identity and self-efficacy which can lessen the negative impact of STEM disciplinary environments for underrepresented students (Estepp et al., 2017; Hurtado et al., 2015; Rodriguez et al., 2019). The development of confidence and self-efficacy are lifelong processes. Students who lack confidence but currently occupy positions within STEM fields may be faced with impostor phenomenon, where they feel like despite their accomplishments they really are not competent in their field (Clance and Imes, 1987). Furthermore, those who are from underrepresented groups may suffer from the negative effects of stereotype threat (Steele and Aronson, 1995), where there is an increased fear of being judged on the basis of societal stereotypes about their group membership rather than their own merit. The psyche of other underrepresented students are sometimes negatively impacted just from being aware of the additional challenges they face because of their identity while being in their STEM field (Pietri et al., 2018). Both impostor phenomenon and stereotype threat can lead to underperformance in academic settings (Clance and Imes, 1987; Steele and Aronson, 1995; Pietri et al., 2018).

Self-efficacy is an essential component to positive outcomes in underrepresented STEM students (Jensen et al., 2011), especially in combatting impostor phenomenon. Faculty-student mentoring is a key component of the student experience that has been shown to significantly influence confidence and selfefficacy (Estrada et al., 2018; Fuchs et al., 2016; Starobin et al., 2016). Mentors act both as guides who share information and as caring friends who provide psychosocial support, including normalizing struggle. Faculty-student connections help students to develop a sense of belonging and positive science 
identities (Zaniewski and Reinholz, 2016). Faculty-student mentoring has also been shown to impact confidence and selfefficacy for student's future pursuits. Both the development of a science identity and self-efficacy are important factors in student's motivation to pursue long-term goals (Estrada et al., 2018).

Mentors are an important source of confidence for students. Having a respected role model who believes in student's potential is vital (Carpi et al., 2017). Formally mentored undergraduate research experiences broaden student's knowledge about career options, prepare students intellectually and technically for further studies, provide the conditions under which a student may fall in love with the scientific pursuit, and provide a boost of confidence for students as they contemplate their next steps (Carpi et al., 2017). Student-faculty mentoring relationships also influence doctoral students as they realize their potential regarding aspirations of entering the professoriate (Alston et al., 2017), indicating that the effects of this mentoring model benefit individuals from grade school through the completion of advanced degrees. Peer mentoring has also been shown to have significant influences on confidence and self-efficacy by fostering professional skills and confidence in developing scientists (Tenenbaum et al., 2014). Peer mentoring has helped in demystifying college and graduate school for students, learning how to prepare for college and graduate school, the application process, and how to plan for after graduation (Meza et al., 2018).

\section{Collaborative Mentoring and the Facilitation of Non-Technical Skills Training}

While collaborative mentoring facilitates the development of confidence and self-efficacy and challenges impostor phenomenon, it also contributes to the development of important non-technical skills. Non-technical skills have become increasingly paramount in student and career success, particularly in STEM fields. Emerging graduates are not only required to have quality technical skills; they also must excel in professional skills to be successful in their respective careers. These skills include teamwork and communication, ethics, global awareness, creative problem solving, and leadership experience (Kulturel-Konak et al., 2013). Hochanadel and Finamore (2015) state, "Faculty should not focus on making just good grades, but how to challenge that person and teach them to create solutions ... teaching a growth mindset and grit facilitates long-term goals and how to achieve them." Technical skills and good grades are important when it comes to success within STEM fields but student and career success is about much more than a grade.

Mentoring has been shown to help expose students to professions, professionals, and professional environments to improve non-technical skills, such as leadership skills and communication. Along with fostering an environment of belonging and support, personal transformation, and professional development, mentoring has also been found to motivate students towards STEM fields, increase leadership abilities and self-confidence, and heighten awareness of the need for diversity in STEM-related fields (Afghani et al., 2013). The LSU-HHMI Professors Program has helped students to achieve various important skills, including: 1) Realization, after attending a learning strategies presentation or meeting that what they are currently doing is not working, 2) An honest commitment to systematically identify exactly what is not working, 3) Changes in mindset about their ability to learn the "hard" subject matter, 4) Committing to work through the plan of action, 5) Following through on their commitment which prevents them from relapsing into old academically destructive habits and ways of thinking, and 6) Continuous improvement which develops sustained personal pride and great satisfaction in the outcome which propels them to maintain what they have obtained (Wilson et al., 2012). Mentoring also demystifies graduate school for students, especially in terms of learning how to prepare for graduate school, the application process, and how to plan for after graduation (Meza et al., 2018). For many first-generation college students, access to mentors opens new doors and prepares them for the college and graduate school requirements.

While it is well researched that mentoring impacts underrepresented students in a variety of ways, students, faculty, and STEM broadly would benefit from developing more intentional, intensive mentoring chains that embed collaborative support, socio-emotional development, and the importance of non-technical skills training. Underrepresented STEM students face unique challenges while attending higher education. Mentors from a variety of backgrounds and statuses within the institution who are eager to help underrepresented students thrive within STEM fields can effectively combat these issues.

The findings of this paper are results from an external, independent evaluation of the WAESO-LSAMP program. The guiding question that led to these results was, "What does mentoring in the WAESO-LSAMP program consist of and how does it impact student participants?" I hypothesized that mentoring would be an important program component that students found valuable for learning STEM. However, as fieldwork progressed, I noticed the variety of ways that mentoring took place within the WAESO-LSAMP program. The remainder of this article details the impact of this style of mentoring for community college students within the Western Alliance to Expand Student Opportunity (WAESO) alliance of the Louis Stokes Access to Minority Participation (LSAMP) program (henceforth known as WAESO-LSAMP). This article addresses the ways that various WAESO-LSAMP intensive mentoring strategies lead to the development and activation of social and cultural capital, the embedding of mentoring chains within STEM environments that incorporate faculty and peers, and the critical skills of resilience in challenging academic settings.

The findings of this research are focused at the community college level. Understanding what occurs within the community college setting for underrepresented students is important for a number of reasons. Community colleges are an important component of increasing diversity in STEM fields (Bahr et al., 2017). Many underrepresented students, especially low-income students of color, begin their studies at community colleges (Contreras, 2011) making it the gateway into more advanced 
degrees if matriculation and transfer are successful. The experiences and opportunities afforded to these students are instrumental in developing pro-academic behaviors and aspirations (Baker, 2013) which can influence their success in obtaining more advanced degrees after their community college experience ends.

Furthermore, detailed information regarding the role that community colleges play in increasing representation of underrepresented students in STEM is lacking (Wang 2013) which is unfortunate, as these institutions have great potential in training a large number of future STEM scholars to address a nationwide shortage of these individuals (Bahr et al., 2017). As the United States continues to debate their role in funding or supporting free or greater access to community colleges, especially for low-income and other underrepresented populations, understanding the various ways these programs and environments impact the future success of these students will only increase in importance.

\section{METHODS OF DATA COLLECTION}

Examining the activities and mentoring within the WAESOLSAMP community college population is particularly useful for this topic. WAESO-LSAMP has been active since 1991, and is one of the original LSAMP alliances. Every year since 1991, the WAESO-LSAMP alliance has consistently reached its goals of increasing the number of underrepresented STEM students within their program as well as their attainment of various degrees. Furthermore, WAESO-LSAMP alliance schools are on track to have equal numbers of underrepresented STEM graduates as the general populations of the states in which they reside, which has been a goal of the WAESO alliance since 1991. Community college participation in WAESO-LSAMP has been strong since 1991, and community college students are given the same opportunities to participate in undergraduate research, conference participation, and mentoring as students at 4-years universities. While most WAESO students participate in undergraduate research, a large number of community college students participate in Summer Bridge programs that are designed to increase the likelihood of enrollment and success at the community college. Since Arizona State University is the home campus of WAESO-LSAMP, it makes an interesting environment for collaboration and transfer between the community colleges and the 4-years institutions in the region.

The first author worked with the WAESO-LSAMP program staff in order to obtain enrollment information from each institution included in a sample of WAESO-LSAMP community college campuses. This information includes student enrollment and contact information as well as faculty mentor contact information. I made first contact by introducing myself at the annual governing board meetings to increase rapport and establish a relationship with campus stakeholders. I also frequently contacted Summer Bridge program coordinators by telephone or e-mail, letting them know when I would be visiting their campus and asking for their help in recruiting students. This included having the faculty mentor or contact send an e-mail to the students letting them know that I was a program evaluator and encouraging them to participate in an indepth interview. Faculty mentor support was critical in recruiting students and gaining their trust. I also made individual contact with students from the enrollment information via e-mail as well as in person at undergraduate research conferences and Summer Bridge activities, inviting them to complete an in-depth interview.

Sampling was two-fold, happening at the institutional and individual level. The first stage in sampling was to select a sample of institutions from the entire population of WAESO-LSAMP community colleges. The program director identified potential institutions as having greater than average numbers of participation or already funded summer activities. Using a non-probability purposive sampling technique, I selected three of these identified programs to be included in the study. All of these institutions are considered Hispanic Serving Institutions (HSIs) and public, associates colleges with varying degrees of transfer and student status. The names of these institutions and their contacts have been redacted to protect the privacy of the schools and participants. It is within this sample of institutions that the second stage of sampling took place. Table 1 provides information regarding each of the institutions.

I used non-probability, purposive sampling techniques to select the individuals to interview in-depth within each institution. The student sample was selected using the enrollment information provided by the WAESO-LSAMP program staff. I completed 46 indepth interviews which took place at Summer Bridge sites, including faculty directed research groups, and immersive summer classes, by the end of my fieldwork activities. Student interviews accounted for 37 of the interviews and 9 interviews were with faculty participants. Of the student interviews, 19 were with students who did faculty directed research and 18 were with Summer Bridge participants. Of the faculty interviews, 4 were independent research advisors and 5 were Summer Bridge faculty.

The in-depth interviews were semi-structured. For students, I assessed aspirations, expectations of the program, program experiences, and suggestions for structuring the program to enrich their experience and enhance their learning. I also asked them about aspects of their lives that might intervene to affect their ability to meet project objectives, such as their family circumstances and demands, their economic situation, and any other issues that might affect their performance in the WAESOLSAMP program. Separate interviews were given to faculty participants where I discussed their program activities, such as mentoring and professional development of students. Table 2 displays the demographics of students that were interviewed as a part of the WAESO-LSAMP evaluation project. All students interviewed for this project identify as underrepresented by race and/or ethnicity within STEM. This is a pre-requisite to participate in the program. While the intersectional identities of these students is important and may influence experiences within the program, the impact of the intersection of race and gender was not addressed in this paper due to time and space limitations and will be explored in future work by the first author.

Interviews lasted between 30 and $90 \mathrm{~min}$, with shorter interviews taking place when students had time or scheduling constraints and longer interviews taking place when two or more 
TABLE 1 | Institutional breakdown

\begin{tabular}{|c|c|c|c|c|}
\hline Institution & Carnegie type & Students & Faculty & Total \\
\hline College 1 & Public, Associate's Colleges: High Transfer-Mixed Traditional/Nontraditional; HSI & 8 & 2 & 10 \\
\hline College 2 & Public, Associate’s Colleges: High Transfer-High Nontraditional; HSI & 6 & 2 & 8 \\
\hline College 3 & Public, Associate's Colleges: Mixed Transfer/Career and Technical-Mixed Traditional/Nontraditional; HSI & 23 & 5 & 28 \\
\hline Total & 3 & 37 & 9 & 46 \\
\hline
\end{tabular}

\begin{tabular}{|c|c|c|c|}
\hline \multicolumn{2}{|l|}{ Student gender } & \multicolumn{2}{|c|}{ Faculty gender } \\
\hline Female & 20 & Female & 5 \\
\hline Male & 17 & Male & 4 \\
\hline \multicolumn{2}{|c|}{ Student Race/Ethnicity } & \multicolumn{2}{|c|}{ Faculty Race/Ethnicity } \\
\hline Hispanic/Latin@ & 27 & White & 4 \\
\hline Native American & 4 & Hispanic/Latin@ & 4 \\
\hline Black & 3 & Black & 1 \\
\hline Middle Eastern/North African & 3 & & \\
\hline \multicolumn{2}{|l|}{ Student Involvement } & \multicolumn{2}{|c|}{ Faculty Involvement } \\
\hline Research Experience & 19 & Research Experience & 4 \\
\hline Summer Bridge & 18 & Summer Bridge & 5 \\
\hline Total Students & 37 & Total Faculty & 9 \\
\hline
\end{tabular}

participants were involved. On average, individual interviews lasted almost $45 \mathrm{~min}$. Participants were asked permission for the interview to be recorded for later transcription. All recorded interviews were transcribed and coded using Dedoose software. I utilized small focus groups in order to maximize the response rate. Of the 46 interviews, 12 students were enrolled using focus groups. These consisted of groups of 2-3 students. Since the groups were small, I was able to gather the same amount of information from the focus group interviews as I would have had they been individual interviews.

\section{RESULTS WITH DISCUSSION}

This section addresses in depth the most frequently mentioned themes discussed by students and faculty as a result of their participation in WAESO-LSAMP activities. Themes discussed include the impact of collaborative mentoring, the mentoring chain that develops through peer-to-peer contact, the impact of the program on student academic growth, and the development of self-efficacy through learning to fail and challenging impostor phenomenon. These themes are each supported by numerous quotes from students and faculty that support the broader message about the process and impact of WAESO-LSAMP programing. I use quotes liberally, as I believe messages are best told through the direct language of participants and their own lived experience.

\section{Impact of Collaborative Mentoring}

Mentoring proved to be one of the most impactful aspects of the WAESO-LSAMP program. Mentoring happened in various ways across the campuses and included one-on-one faculty mentoring with students who do faculty led research projects, peer-to-peer mentoring, as well as broad group mentoring that occurred during Summer Bridge programs. Of particular interest here was how mentoring networks provided support for professional and academic development, how faculty driven recruitment led to the development of self-efficacy, how learning to fail helped challenge impostor phenomenon, and the importance of mentoring to teach more than just technical skills and abilities.

\section{Academic Development and Student Engagement}

The relationship developed through faculty-student mentoring provided students with opportunities necessary for professional growth and success, including formal and informal networking and coaching on how to present research across various academic spaces in their exposure to academia. For many students, WAESO-LSAMP provided their first experiences in these areas. These formal, guided interactions within academia provided students with more than just hands-on learning that results in developing technical skills. Faculty mentors additionally give students opportunities to gain social capital through networking. This social capital is crucial to progression in the field and higher education. This sentiment is highlighted in a quote that a WAESO-LSAMP student internalized from her faculty mentor, "The most valuable thing, (mentor] used to say was this," "Never close a door on an opportunity."

\section{Transition Into College and Impact on Confidence}

This formal guidance through academia with a trusted advisor is particularly important for traditionally underrepresented students in STEM. Students often started out their WAESOLSAMP experience feeling apprehensive and doubtful about their abilities and their likelihood of being successful. However, through working with mentors who recognize their potential, students slowly begin to realize their own abilities and potential for success. Mentors were able to identify students with potential that were unable to see themselves in certain roles because they are intimidated and doubtful of their own skills.

Faculty mentors encouraged these apprehensive students to apply to things like internships, research opportunities, as well as present research, even if they have had little experience presenting. It is important for students to be able to work with faculty who know the process and procedures of higher education and that the experience gained by participation in such activities, regardless of whether or not the student had ever presented before, is a normal and necessary part of the growth of the science identity and future success. This targeted influence 
also resulted in students gaining opportunities and support outside of their individual WAESO-LSAMP project. Here, a student notes how their encouraging WAESO-LSAMP mentor influenced their successful application for external funding. "There's a scholarship here with (a stem program), so she was like, "Oh, you should apply," and I was like, "I don't think I'll get it," and then I applied, and I got it.

\section{Challenging Fears of Failure and Impostorism Through Experiential Learning}

Students often start out their experiences with fears of failure or not being qualified for the work. "At first, I was kind of like really, me? Like you want me? Because I felt like when I presented, I stumbled a little too much ... are you sure you want me on your team?" However, through the hands-on, challenging environments, students become empowered by the scientific method and how mistakes do not equate to failure, but actual growth-whether through scientific discovery or personal improvement.

I was afraid I would mess up a lot, because the word research on its own is kind of intimidating. So the research, the word, we give it so much power so that it intimidated me the first time, but once I was in it and I saw how (WAESO-LSAMP Mentor) was doing it so fluidly and we were so rigid, we were being so careful with everything. But by the end the semester we were the ones doing things at the same pace as [mentor].

Through these hands-on, authentic research experiences with faculty sponsors and their peers, students learned self-reliance, independence, trouble-shooting, and how to work on group projects with high pressure deadlines. Student research experiences in WAESO-LSAMP also opened their minds to opportunities that they had not yet considered for their academic lives. While many students aspire to be medical doctors, learning the process and problems of research and becoming engaged with academic life at their campuses inspired them to merge those areas, aspiring for Ph.D.'s alongside a medical degree.

Having that experience with (Mentor) made me want to do $\mathrm{MD} / \mathrm{PhD}$, which gave me understanding that I need to keep moving forward and I need to work really hard to be an eligible candidate for that program, for all the other programs. So in a way, that did help.

Through extended engagement in activities, students were able to capitalize on their increased motivation to accomplish their goals. These included traditional goals of graduating from community college, getting accepted and transferring into 4years colleges, receiving competitive scholarships, winning awards, and formally joining the STEM industry job force. WAESO-LSAMP mentors are aware of the important connection they have with the WAESO central office, and see themselves as a team, working together to reach shared goals regarding student success and transfer.

Both institutions mutually benefit from this shared commitment and the partnership created through WAESOLSAMP, as faculty and sponsored environments are doing necessary work to inspire, prepare, and socialize students so that they are excited to transfer and continue their academic journeys. By engaging with these environments, underrepresented students who had experienced challenges within traditional academic environments were no longer discouraged from seeking transfer into a larger research institution. Instead, they reframed their ideas about faculty and university life where faculty were supportive and presented themselves and their environments in such a way that students could visualize themselves in that position someday.

\section{Faculty Driven Recruitment and the Development of Self-Efficacy}

WAESO-LSAMP's unique mentoring strategy also has an impact on the development of self-efficacy and self-esteem. The mentoring relationship begins at the time of recruitment and is often faculty driven. Faculty are given freedom to reach out to students who they see as promising, regardless of traditional signifiers of success like exceptionally high grades or prior experience. The only requirement is that the student be part of an ethno-racial group that is underrepresented in STEM. Students are not filtered out due to low GPA or lack of experience in a research lab or in the classroom. Faculty mentors frequently discussed how they sought out students who may not have been qualified for other programs, and students sometimes discussed how they had been overlooked by other research programs due to GPA or other factors. This results in students who have non-traditional signifiers of promise being admitted into an environment where they can work on weaknesses within their academic portfolio through intensive experiences and does not simply allow only the already successful students to be granted entry into these important spaces. without other restrictive requirements that often filter out low-income, first-gen students of color (GPA, prior experience, letters of recommendation, Students mentioned that they feel honored and special when singled out by faculty to do research for them, which boosts their confidence.

I was just honored to have someone like her like say, "hey you want to do this, like you want to come over here and do this with me and with the people that are doing this?"...I was excited because I felt privileged because she's already had it going on, and she explained the research to me, and I thought it sounds important, and I liked it, so I was really excited to get on.

Faculty mentors talk about promise and potential in ways that challenge traditional recruitment methods, like high GPAs, prior experience, and formal recommendations by other faculty.

When faculty have freedom to select students they see as promising, it results in dedication to their recruits. Their dedication contributes to the creation of an environment where students feel like their mentors authentically care for them and their success. In turn, students are encouraged to seek out resources and experiences because they feel like it is a welcoming, supportive environment (Beals, 2019). "[Mentor] kind of inspired me...to go [to Summer Bridge] because...the way he said it--it didn't sound like a teacher or professor that was talking to me it kind of sounded like he was a brother. Like a big brother or you know like a homie or something like that." Through these experiences, students begin to rethink what it 
means to work with a professor and develop skills to practice resilience in the face of challenges, resulting in them thriving in a challenging environment (Hochanadel and Finamore, 2015; Revelo and Baber, 2018; Beals, 2019). It was often the case that supportive and friendly mentors played a significant role in creating these welcoming spaces. This is especially important for students who are first-generation college students and other underrepresented students in higher education.

\section{Authentic Caring and the Impact on Retention}

Faculty mentors effectively showing that they care for their students has a positive impact on the student's self-concept, science identity, and motivation to continue working. Students often noted that they like having people who supported them because it pushed them to work harder. Here, a student notes how having a supportive mentor influences her to keep working hard and to not give up. "Knowing that I actually have, you know, people that support me ... I actually do better. As in I might not do the best, but you know I won't give up."

Students frequently noted that one of the greatest things they got from their faculty mentor was an increased excitement for the work, doing research, and their STEM field. Faculty mentors are excited about the projects they bring to their students, and their excitement and support influences the student's own feeling about the work. Part of this comes from the faculty rewarding traits that are central to science-curiosity and engagement (Beals, 2019). This is often a trait that faculty seek out when selecting future mentees. "I was the one student that asked all these questions in [mentor's] class and she was like "I like your curiosity" I was like "okay, I'll use it." That was amazing ... I really loved that class. It changed everything for me."

WAESO-LSAMP faculty are aware of this impact and how important getting students excited about science is for their engagement and retention in the field. Here, a faculty mentor talks about this important part of the mentoring relationship. "It's really, I think it's that mentorship, the excitement of science starts to, you know, we stoke that sort of spark into a flame. And I'd say that is the biggest one." Faculty also frequently help students realize the real-world significance of the work that students are doing, translating lab procedures into altruistic outcomes, which helps students develop a passion for doing STEM work. This increases student engagement with the projects, which is important for retention. Faculty are aware of how important this is and work with students to incorporate their individual interests and questions into their research project, even if it was extra work. "She always went out of her way for us ... She always saw what I was interested in and she never blocked me or told me it's time (to leave)."

\section{Learning the Positive Impact of Failing}

In order to understand what factors contribute to effective mentoring, I frequently engage students in a conversation where they can express in their own words what they see as an effective mentor. Students shared similar ideas about what makes an effective mentoring relationship and whether or not WAESO-LSAMP faculty fill this role. The most frequently mentioned qualities that students seek in a mentor include availability to reach out and ask questions, support during the process of sponsored activities, encouragement when things get hard, empathy in the face of mistakes, and authentic engagement with students. Summer Bridge students especially mentioned how different it was to work with WAESO-LSAMP faculty as opposed to their high school teachers. For example, one student mentioned, "They are not like teachers, or how it was in high school. They make you feel like they're friends, you can talk to them." Students also mentioned that they felt a great deal of encouragement and motivation to keep working hard, and how good it feels to work through a project that was challenging. These interactions help decrease the distance between faculty and students, especially first-generation students, and lead to more enjoyable college experiences. The ability to recognize when students are struggling and need extra help and encouragement was important for students. Students, especially underrepresented students, are not always confident to reach out and ask for help in fear that it will negatively impact how faculty view them and their potential, which may amplify the negative impact of impostor phenomenon (Clance and Imes, 1987). Students were appreciative that faculty were able to "scan the room" and recognize when someone is not doing well and then reach out to help solve the problem.

She knows how to scan the room and be able to determine when a student is not doing as well as she would like ... she's able to understand the area they need more help in ... She's gonna find a way to help you get what you need ... You see people who are like If there's a mistake made, you can see that they're super angry or irritated, and she's just calm ... She's like, "It's fine. We're gonna fix this." It makes it easy to keep going, learning, and building from those mistakes.

This type of sustained and empathetic support and encouragement is critical for the intensive mentoring model. It helps students realize that making mistakes is often an integral part of the scientific process and the development of self-efficacy. One student noted a positive transformation in learning to fail, saying, "Now when I make a mistake, I know how to approach it, you know?" Through this work, students learn critical skills like independence, self-reliance, and how to thrive in the face of failure. Students frequently mention how empowering it is to learn how to fail effectively.

I was nervous ... I don't want to mess up and I don't want to ruin everything. But (Mentor) did mention 1 day, "In research there are no mistakes. Because your mistakes could lead to something better." And then she mentioned one other research student that was there a semester before, her mistake actually improved the project. So that gave us a little bit of confidence right there. But the reason I enjoyed it most is when that mistake happened, because I was excited to figure something else out, something new.

These skills translate into real-world success once the WAESO-LSAMP experience is over. I had the opportunity to talk to students who had since transferred to 4-years colleges or universities as well as the workforce about any impact their experience had on their success post-WAESO. These students noted that the mindset they were able to develop through learning 
to fail effectively made them more successful in their current endeavors.

The development of this confidence and self-reliance resulted in the former student being able to trouble-shoot on the job and come up with a solution to a problem that his organization was having, using tools he learned through WAESO-LSAMP activities. "The first time I did it, I used their (Institutes] methods. And it didn't work, the bacteria didn't grow. So, the second time, I decided, "I'm not going to do the same mistake again," so I just did everything [Mentor] taught me ... and it grew."

My work interviewing faculty mentors suggests that they have found a way to strike a balance between letting students figure things out on their own and guiding them when needed that results in the student developing important industry and technical knowledge, self-confidence, and independence. These mentors are aware of this important process and how challenging it is to facilitate. One faculty mentor explained that the method of allowing failure is less cost-effective and less efficient.

She (non-WAESO-LSAMP mentor] can probably get that same task done in 2 weeks that I can do in 2 months. But the learning experience that they built in 2 months is, failure really brings on the successes ... I don't get the same successes that they do, because they can take a student that just started and get them to a point that they are doing high impact posters. For me, it might be a lot slower, but I think through failure you get a lot more successes.

Despite being less efficient or cost-effective, this method allows for the best learning because students fail and learn from their mistakes or learn something entirely unexpected. Not only is this good for the development of these important soft skills, but this approach was also described as less intimidating and helped students feel excited and engaged instead of frustrated and discouraged. It is also important to note that the WAESOLSAMP faculty are aware that this method of mentoring is not always practiced by non-WAESO-LSAMP faculty within their institutions, suggesting that this intensive mentoring may be challenging the traditional culture of STEM education.

\section{Challenging the Impostor Phenomenon}

The intensive mentoring that challenges traditional culture of STEM education is seen by faculty as integral for the type of growth and development necessary for student success. These environments that embrace the challenging environment of STEM research and learning while providing socio-emotional support to the student during the process of failing upwards help students reframe their views of higher education (Monarrez et al., 2019; Nevin et al., 2008; Revelo and Baber, 2018). Through their work with WAESO-LSAMP sponsored environments, many students mention that they realized their internalized selfdoubt and fear was a part of something much bigger than themselves. Faculty helped them put a word to this-impostor phenomenon. Realizing that this was a phenomenon that many people, including their own mentors, experienced helped students overcome their self-doubt. Here, a student brought up learning about impostor phenomenon from their WAESO-LSAMP mentor and how they learned to manage these feelings. It is important to note here that the student brought up impostor phenomenon without me specifically asking about it. They mentioned this lesson as one of the beneficial things they learned through WAESO-LSAMP, therefore I probed them to speak more about it.

Out of the six boxes she had (on impostor syndrome), like the categories, I checked off five, all but one ... I was like, "Oh my God! Okay.” Before that, I never knew what term to use for it. I thought I was just expecting a lot of things from me. But turns out, its impostor syndrome...I remember her mentioning one part saying "Give yourself a pat on the back." I don't do that, though. But I kind of try to compliment myself. I tell myself, "Hey you did this. You're good. Now on to the next one." I keep telling myself those things.

Sometimes student's feelings of self-doubt are so strong that they question their abilities to be successful beyond WAESOLSAMP. A number of students mentioned how important their WAESO-LSAMP mentor was-even when the students had been working with them for a semester or more-in terms of encouraging them to seek out experiences to help them grow beyond the WAESO-LSAMP environment. A nudge or statement of support from a faculty mentor can make all the difference in where the student goes next after their time at their community college.

First off, I was flattered. I was like "What, really?" You know. "Me?"...it was my first actual research. You know the impostor syndrome kicking in again from all angles ... Then I asked her, she was like... "You've done everything good." And then she was like "You've got the skills don't worry." And then after that we just started building.

This sustained support for their students proved to be an effective strategy to help the student succeed once finished with their WAESO-LSAMP activities. Students often began seeking out other opportunities that they might want to try and went to their faculty mentor for support and guidance. It is important to note that faculty mentors are explicit about the competitive nature of some of these non-WAESO-LSAMP research experiences. In fact, they are aware that many underrepresented students in STEM face great challenges in terms of acceptance to these more competitive programs. They teach their students about the competitive nature and support them in their efforts. Here, a student discusses one time when this happened with them and how their mentor's support led them to success, even when their impostor phenomenon remained.

I told her (mentor) "I heard about this internship." She was like "Yeah, that's great. Go for it...It's not going to be that easy to get in.". . She told me to apply there and then I applied ... She wrote me my recommendation letter ... And then I was waiting for a decision and then I got accepted. Yay, I got accepted...The director of the whole internship thing [e-mailed me] and she told me I was one of the best profiles. I was like "Maybe you got my resume mixed up. Not, that's not me."

\section{Student Accomplishment and Growth of Self-Efficacy} One part of helping students manage their impostor phenomenon utilized by WAESO-LSAMP faculty was a consistent emphasis on helping students recognize their own 
worth and potential while reminding them that their accomplishments were no one else's but their own. When working in such collaborative environments with a dedicated mentor, it is easy for students with self-doubt to forget that what they accomplish is "theirs" and a reflection of their own hard work.

I wanted to learn more about what environments foster this growth of confidence and feelings of self-efficacy. In my conversations with student participants, it became clear that the WAESO-LSAMP sponsored conferences and programming were often mentioned by students as being a catalyst for the internalization of feelings of pride and their own ability to be successful. Students that I spoke with mentioned that just presenting research gave them more confidence in their own abilities to do science. Presenting outside the walls of a classroom and in a formal academic setting with students from many other universities and programs is not something that can easily be replicated within a traditional classroom. This added component of competition, common in the academic world, is unfamiliar and uncomfortable for students. However, it results in students feeling more confident in their own abilities, increasing feelings of selfefficacy and overall pride in themselves and their own work, and also the confidence to continue this work in the future, despite their original feelings of being a fraud.

The second conference we went to It was like, "Oh, this is a breeze." It was so much better. And then time had lapsed, so I felt like I knew what I was talking about. I had put research in, so I wasn't so scared about feeling like I felt like a fraud (the first time.) I was there, like, I feel like this isn't my research. And I'm trying to present it. But it was a good experience ... Then later on, I was like yes. I feel better about it.

While presenting in and of itself was beneficial for student's sense of accomplishment, self-worth, and challenging the impostor phenomenon, the opportunity to be formally recognized for their work through winning awards was particularly powerful. For many students, this was their first experience doing real research and presenting it in a formal setting. To be recognized formally with a tangible award was a big moment for their academic careers. Students who won awards or even just received a plaque for presenting noted how powerful this was for them, and proudly displayed their formal accomplishment for their friends and family to see.

Like those conferences. I've never done anything like that. It feels good. I feel like I'm doing something. I'm presenting something. And I can be proud of it. I have my little plaque they gave us from WAESO and have it on my shelf ... I'm like, "Yay!" I'm so proud of it. Everyone asks. I'm like, "Yeah, I went to a conference. I presented something." It's something to be happy about, something to be proud of.

It is important to note that large scale efforts-like hosting or attending a conference-are not required to foster this type of growth in students. In fact, many students noted what they saw as the "little things" that they learned through WAESO-LSAMP that slowly accumulate and lead to feelings of greater self-efficacy and lessen impostor phenomenon. Note this remark from a WAESOLSAMP research student. "It's kind of difficult to have a huge dream. But the little things you do, that kind of seem silly, they help you, they motivate you, they give you that feeling that it has already happened so maybe you can have a positive outlook about it."

\section{Socio-Emotional Mentoring and the Impact on Student Success}

These smaller scale actions might include the care that faculty put into establishing relationships with their students that lead students to feel more confident reaching out for necessary support and guidance. Underrepresented students often enter college feeling apprehensive about approaching faculty and asking questions for reasons that may be associated with impostor phenomenon (Clance and Imes, 1987). However, WAESO-LSAMP environments were effective in diminishing this fear and led to students feeling more confident to reach out for help when needed. "What I learned is that when you need help, ask the instructor. Don't be scared. It's going to prepare me for college. I feel like I'm gonna struggle a little bit and I'd be afraid to ask the instructor for help [prior to Summer Bridge]."

Faculty are aware of the importance of fostering this type of socio-emotional growth in their students and some even believe it to be more of a priority than the academic programming that they provide. I had an in-depth conversation with two faculty mentors at one of the campuses. These faculty were both involved with Summer Bridge and one was a frequent sponsor of individual student research projects. While this excerpt is lengthy, it is important to share because of how they articulate very clearly their role in fostering confidence and self-efficacy, rather than reinforcing negative stereotypes that often follow underrepresented students through the educational pipeline. It is also reflective of the many conversations I had with WAESOLSAMP faculty across the three campuses.

Mentor: What I've found is that students who come in and test underprepared or first-gen students or any kind of nontraditional student, the problem $90 \%$ of the time is not academic. It's one of learning the rules and one of confidence...of academia ... Because that's not their language. And so, that's why we do what we do. Because that's, it's not an easy fix. But for too long, we've just focused on, "Oh academics, academics." And that's not what it is. So we spend a lot of time building up confidence ... the students are here like all month. So it gives us a lot of time to like help build that confidence. ...get to know them ... Over the course of like a week or two, or about 2 weeks into it, by time we hit say July, students are much more comfortable. They'll come here. They'll hang out. (Faculty Mentor 1) is less scary, you know, all those things ... And because of this and because of our attitude toward them, that's really what we're looking at. Our success rate is always in the 90th percentile ... And we don't lower standards ... and when those, you know, bottom levels of Maslow's hierarchy are served then they can open up to the learning.

I added emphasis to the statement, "and we don't lower standards" because often, programs that target underrepresented students are accused of either only selecting already high performing students or lowering standards so that their program appears successful. It was made very clear by all faculty involved in WAESO-LSAMP that they do not lower their 
standards or expectations for these students. They are adamant that their success is not based on choosing only high-performers (they recruit from schools with low transfer rates and include students who were not the highest academic performers.) And their student's work results in multiple conference presentations and presentations that win awards. Their students transfer, and enter the private sector where they are successful.

\section{Embracing Failure on the Path to Success}

Part of the message that faculty are also adamant about-as mentioned above and reiterated from another faculty member below-is the importance of embracing failure and struggle in order to be successful. The emphasis on this as a central component of WAESO-LSAMP sponsored teaching seems to have had a profound impact on students and it is intentional.

Faculty: Science is tons of failure. That's all science is ... So they have to learn how to fail...I think it's super important to fail...We are sitting down and talking like colleagues now. We are not teacher/mentor anymore and that change is huge and that only comes from failure. (emphasis added) If it happened the first time every time it wouldn't mean as much I think. So the struggle of maybe 5 weeks of failure and then all the sudden this giant success. It's huge.

It was interesting to see how excited these experienced professors were about the prospect and process of failing. These individuals are in their career because of years of objective success and the ability to navigate challenging and competitive environments. Based on my conversations with them, I found that teaching how to fail upwards, to embrace failure as an important part of academic growth and accomplishment, is central to their work with WAESOLSAMP students. This helps students reframe their own struggles and challenges in a way that promotes growth, curiosity, and excitement rather than deters them from pursuing their goals because they feel like they are not good enough. By working through failure, they are becoming part of the community that they wish to join.

You can ask (mentor)...I was so curious. [The experiment failed.] And, I was pretty excited for that. But that excitement I want to hold on to ... I want to keep getting that excited when I figure something out or something goes wrong and I have to figure something out ... That was what helped us most ... There were a lot of times that I made a mistake, but the best part was [mentor.]

Faculty here effectively teach students that a failed lab experiment is not a reflection of the potential or worth of the student in the lab. Instead, they reiterate how important failure is in the scientific process. It becomes a critical lesson and learning experience for the student which results in a mindset that allows for non-linear paths to success as students grow beyond their first failed experiments. This helps students develop critical resilience and the confidence to troubleshoot, which contributes to students seeing "mistakes" as an exciting aspect of the scientific process, resulting in greater creativity and growth (Hochanadel and Finamore, 2015; Revelo and Baber, 2018; Beals, 2019) rather than as an individual failure.

\section{The Mentoring Chain-The Value of Integrating Peer-To-Peer Support}

It is clear that intensive mentoring by faculty positively impacts the student-faculty relationship and student growth. However, my work with students also suggests that it also results in the organic development of a community of support. In my conversations with both students and faculty, the impact of peer-to-peer interaction and support emerged as a unique and effective strategy that faculty applied-whether directly or not. We refer to this phenomenon as "The Mentoring Chain," which consisted of a faculty mentor who led the team of students, who also mentored each other inside and outside the lab environment. This was often an intentional process from faculty, who would work with students for more than one summer and then put them into a leadership role with newer recruits. This type of environment encouraged students to lean on each other for support and encouragement, creating an environment of collaboration rather than competition. "It's easy for a student to ask another student a question. It's hard for a student to ask a teacher a question."

\section{Growing Through Mentoring Others}

Students mentioned finding themselves mimic the type of mentoring they received from their WAESO-LSAMP mentors when working with their less-experienced peers. This not only helps the students learn proper lab techniques, but also gives them the opportunity to develop confidence in their own abilities and develop important leadership skills.

I approached it just like (mentor] showed me how to do it ... It kind of gave me experiences ... I would go to the students and tell them "Make sure you do this, make sure you do that"... But then after the third week we started doing everything together. It was fantastic.

Some student mentors had opportunities to mentor high school students and give presentations about the paths available to them in higher education. This allowed students the opportunity to develop their own mentoring skills and also engage with students who shared similar experiences and backgrounds in a way that promoted a community of support and guidance throughout the entire transfer pipeline. Students reported feeling that peer mentorship was a rewarding experience.

You get a bunch of different opportunities (from WAESOLSAMP). And then at the time I was tutoring at a high school ... [We] presented there at the high school too. Yeah kind of like show the different paths that you could take... You would have people at the community college go and talk to people, or students at like a high school. And then as you transition from the community college to a 4-years university then you could mentor the people that were at the community college as a student at the university ... I did the Summer Bridge program and now we get to help the new incoming students ... we are their guiders technically. 


\section{The Varied Approaches to Mentoring Communities}

Conversations with student and faculty participants revealed that peer-to-peer mentoring took many forms. However, the most frequent aspects mentioned by participants included the opportunity to take a leadership role in teaching other students how to do technical STEM skills that they had learned from their mentor, including tips and tricks that a student learned in the past that they can now transmit to the newer student. Beyond this technical learning, students also practiced the same type of support and development of soft skills with each other that faculty found important. This included frequent checking in on each other's well-being, encouraging team members when things were challenging, collaborating to reach a common goal, and celebrating individual and group accomplishments. This influences students to see STEM education environments as collaborative with shared accomplishments rather than overly competitive.

[Peer Mentors] definitely helped. I would say [Student 1] took the lead, and he really showed me how to do things. He was very helpful as well. I feel like, by the end, we were on top of things. If I couldn't be there, then [Student 2] would be there. If [Student 2] couldn't be there, me and [Student 1] were there. We all would just like have each other's back.

Overall, mentoring in WAESO-LSAMP is a long-term, integrative process that begins at the time of recruitment. Faculty desire that the mentoring relationship evolve organically and know that the process of how students get involved with a mentor in the program is an integral first step. Students feel honored to be singled out but are often apprehensive about their skills. Faculty use non-traditional indicators of student potential, beyond GPA, and are in turn dedicated to serving their student recruits holistically. Faculty show a great deal of excitement toward their work in WAESO-LSAMP sponsored research, and in turn get students excited about the work while encouraging students to develop individual interests related to the work.

Mentoring then involves a great deal of professional and academic development. These might include the more direct or traditional things a mentor would help the student navigate, including various forms of professional networking, exposure to the academic world, and opportunities to engage in academia. Alongside this traditional mentoring, faculty engage with students in a way that transcends technical skill development. This work might include the less obvious roles that an effective WAESO-LSAMP mentor might play. This is where a student will develop soft skills necessary for successful college completion and academic life, easing the transition from high school to college largely by being a point of contact when the student officially arrives on campus, and carefully considering the unique needs of underrepresented students.

\section{Non-Technical Skills as Essential to Academic Success}

The development of soft-skills, or other non-technical lessons, was discussed by faculty mentors and students alike. It is through the development of soft skills that students learn important qualities associated with being successful in the lab, the classroom, and in life working in STEM. Faculty mentors pass on important, non-curriculum information like time management, how to engage with professors, and how to navigate higher education in general. Here, a faculty mentor discusses the importance of this component of WAESO-LSAMP programming.

Besides the content of the actual class, themselves? Just how to prepare, how to successfully navigate a college class, whether it's learning how to come to office hours, how to contact the instructor if you're going be late, stuff like that. Just, things that are going to make you successful, being on time, attendance, having stuff done. College instructors don't give a lot of, "well, can you just bring it tomorrow?" That sort of thing, so, just getting them in that mindset of - it's a whole different level. It's like going from college athletes to pros.

This type of mentoring and support also helped students as they transitioned from high school to a college environment, or from the community college to a 4-years college and university. WAESO-LSAMP mentors are acutely aware of how important this type of engagement is for the students that they serve, often first-generation college students with little family support on how to navigate college campuses and transferring. One student spoke specifically about how having this type of mentorship made the Summer Bridge program especially meaningful and engaging rather than just a "get in, get out" summer class where she received class credit, but a starting place for a community that she had where she could find support whenever she ran into issues or had questions at her campus.

Having a point of contact for students transitioning into college was important because they knew where to go first when in need of help during their first semester. This is particularly important for students from underrepresented backgrounds, and faculty mentors take great care in making sure they are there to support these students and their needs as they prepare for and transition to the college environment. Faculty mentors frequently mentioned the unique position of non-traditional and low-income students and how their needs may differ from the needs of traditional students and their experiences. When probed about what faculty who work with underrepresented students should keep in mind when working with their students, mentors noted the importance of being understanding, empathetic, and a resource for these students and how this support network is an intentional aspect of WAESO-LSAMP program environments.

Students and faculty both mention several important traits of a quality mentor, including being empathetic, understanding, dedicated, and caring. However, quality mentors also help students identify aspects of impostor phenomenon while encouraging them to embrace failure as an exciting aspect of academic life, not one that signals lack of fit. Faculty mentors need to have compassion and empathy to greet students with positivity when they make mistakes rather than signaling a fatal flaw on the part of the student. This transfers into real-world success, independence, and self-efficacy. It is important to note that this process-while successful-is seen as less cost-effective and 
efficient than traditional mentoring, but yields what faculty see as great success.

\section{Embedding Social Capital Through Intensive Mentoring}

Beyond feeling more prepared for college, WAESO-LSAMP students frequently mentioned the benefits of being connected with various social networks and building their social capital. Students specifically mentioned the benefits of being connected to faculty early and the impact it had on their relationships, work ethic, and their academic success, which they feel contributed to their positive experience within the program. As discussed prior, this intentional mentoring has a tremendous impact on students. However, it became clear that through working with WAESOLSAMP faculty, students found that they were in general more connected to the campus and felt like they belonged when they saw their former mentor in their new, non-WAESO-LSAMP environment. "After (mentor] taught us ... there was a gap and I needed to take [a class that] was taught by a different teacher. But during that time, I was in [science club], so [former Mentor] hung out in the lab...She knew us."

\section{Interpersonal Support as a Means to Other Opportunities}

This interpersonal support positively impacted their academics and students report continuing to use those connections to identify other resources and be successful outside of WAESOLSAMP sponsored environments on campus. Students were positively impacted by faculty, staff, and teachers that contributed to their positive academic experience. They have also continued to use these individuals as important resources as they navigate college. Students frequently mentioned that when things got difficult for them, "I would talk to (mentor] and then the coworkers I had here, since they had already taken multiple classes or the same class. I'd be like, "What did you do?" And ask for advice. That really helped." Some students also mentioned that this interpersonal support contributed to their inclusion into the campus culture and community, while still having caring, supportive, and empathetic teachers.

I think it was maybe like the shift from being like a like a high school student. Everybody's (WAESO-LSAMP] like, you know checking on you and just like making sure that you're okay. Especially like I said when they describe that to you in college, they're [high school teachers] like, "You're on your own. Nobody's going to ask you anything. You've got to figure everything out yourself." And [WAESO-LSAMP teacher] was like, looking at my grades was like, "Hey, come here. Did you make sure you get this in?" I was like, "Oh my God, thank God for you." Like it's still he's got like, that teachering thing, but it still gives you like independence also.

Overall, students found their WAESO-LSAMP experiences to be better or more beneficial than anticipated, easier than they expected, and much more accessible than they had been led to believe from their high school experiences. The formal and informal mentoring chains, access and exposure to college classrooms and environments, and the development of important skills led the students to feel prepared for college, comfortable on their campus, and with a mentoring chain to activate when things started to become confusing or challenging.

Interpersonal support from both peers and faculty also contributed to students having a more positive experience with the Summer Bridge program than they originally expected. Respondents utilized these connections continually in their future academic ventures, which also contributed to some students re-thinking prior plans as a result of their experience in the Summer Bridge and committing to stay at their respective campus.

At first, I actually didn't want to come to (current campus). I was like, "I wake up to it every morning. I want to go somewhere different." But then [Summer Bridge Director] came to our school and talked about the program and then I did the program and I just ended up staying because I liked it and then how I had someone that I knew could help me, not just for that summer, but for when I was actually here. It was very helpful because I was overwhelmed with college.

Students often mentioned that the connections that they made with their WAESO-LSAMP peers positively impacted their academic experiences and outlooks while also providing them skills to navigate the collegiate environment. This seems to stem from the collaborative network of peers, or a cohort effect, that develops after students engage with each other, from similar backgrounds, over a period of time. "It makes us united and then you have friends around campus which is very good. Helpful." Another student echoed this sentiment, and described specifically how recognizing that they had a shared background with their peers and the realization that they were on an equal level with them created a sense of a community that results in a network of support even after WAESO-LSAMP activities conclude.

It was cool because you got to ask them about how it was, or to see like, okay, we're taking the same levels. It was just cool because you got to meet them and experience everything with them and you got to keep those friends and possibly see them in other classes as well and just keep in touch because "I know we made friends during the summer that are still our friends and we still take classes with them."

Intensive mentoring, the development of formal and informal social support systems, college preparation, and the impact on academic growth result in increased engagement amongst WAESO-LSAMP students at their respective colleges and in their future plans. Regarding engagement, students primarily discussed how WAESO-LSAMP environments impacted their own academic and professional goals through the creation of a collaborative and mutually supportive environment of peers and advisors. This engagement had a positive impact on the development of selfefficacy, a commitment to academic goals, and feelings of empowerment to reach desired goals, especially in terms of challenging the impostor phenomenon and fears of failure.

\section{CONCLUSION AND IMPLICATIONS FOR PRACTITIONERS}

WAESO-LSAMP programs have similar goals in extending their students opportunities to engage in hands-on, high level research 
with faculty mentors and influence feelings of belonging on campus. Summer Bridge focuses on preparing students for their first semester of college in terms of practical skills like time management and scheduling, but also focuses intensely on creating an experience where students develop confidence and self-efficacy to be successful college students.

Overall findings suggest that WAESO-LSAMP activities positively impact community college students in terms of selfefficacy. Students frequently mentioned having more confidence in their ability to transfer to a 4-years college, obtain a bachelor's degree, and advance toward graduate education. They also developed more confidence in terms of reaching out to and working with professors and navigating the social and physical environment of college. Being exposed to a community of peers and supportive faculty was a significant part of this growth in confidence. This has implications for literature regarding the importance and impact of developing a growth mindset, and how academic environments can foster this important aspect of resilience and success for underrepresented students (See also Banda and Flowers, 2017; Revelo and Baber, 2018; Beals 2019).

Students noted that WAESO-LSAMP activities positively impacted them in terms of finding themselves as part of a supportive community of students who had similar backgrounds as well as faculty who were ready and willing to work with them and make them feel like they belonged at their respective campus. Students expressed gratitude regarding the familiarization of the college environment and college life. These participants (often first-generation college students from lowincome backgrounds and students of color) became familiar with campus activities through the WAESO-LSAMP Summer Bridge and developed an understanding of the institutional culture and climate of higher education. This helped them establish a sense of community for actual and prospective students alike, in that they get to know faculty, staff, and other students who they can reach out to for encouragement and support.

Program leaders mention that one of their primary goals is to expose students to the campus environment to show them that they have what it takes to be successful, demystifying this environment. Students concur, and often speak about their increased confidence in being able to navigate the community college environment, STEM education, and bureaucratic processes such as locating and applying for financial aid.

This appears to have a positive impact on student's likelihood of enrolling and persisting in their studies at a community college campus, although future follow up studies would need be to be conducted in order to assess whether or not this was the case once it came time to enroll. Some WAESO-LSAMP activities that certainly showed promise in supporting these objectives and

\section{REFERENCES}

Afghani, B., Santos, R., Angulo, M., and Muratori, W. (2013). A Novel Enrichment Program Using Cascading Mentorship to Increase Diversity in the Health Care Professions. Acad. Med. 88, 1232-1238. doi:10.1097/ ACM.0b013e31829ed477e impacting the academic and professional development of students include hands-on research with faculty and opportunities to attend training sessions and academic conferences, which are important for students' professional development and for seeing themselves as a member of the academic community in which they strive to be included. Opportunities for one-on-one interactions with faculty mentors along with ones for networking and peer-mentoring other students was also frequently cited by students as benefits of being a WAESO-LSAMP student. Faculty mentoring taught not just technical skills in STEM research, but also focused on fostering confidence, self-efficacy, challenging the impostor phenomenon, and learning to fail effectively.

\section{DATA AVAILABILITY STATEMENT}

The datasets presented in this article are not readily available due to issues of privacy and confidentiality. Requests regarding this should be directed to Rebecca Beals, rebecca.beals@unco.edu.

\section{ETHICS STATEMENT}

The studies involving human participants were reviewed and approved by University of New Mexico IRB Maricopa County Community College District, IRB. The patients/participants provided their written informed consent to participate in this study.

\section{AUTHOR CONTRIBUTIONS}

$\mathrm{RB}$ is considered the first author of this paper and was responsible for the design, data collection, analysis, and structuring of the paper. SZ, FL, and OB contributed equally to literature review, idea sharing, and assisting with writing and referencing as last authors.

\section{FUNDING}

The first author disclosed receipt of the following financial support for the research, authorship, and/or publication of this article: This research was made possible by the support of the National Science Foundation, NSF Grant Number 1619524 Sub-award Number 17-037. This independent research and the views expressed here do not indicate endorsement by the sponsor.

Aikens, M. L., Robertson, M. M., Sadselia, S., Watkins, K., Evans, M., Runyon, C. R., et al. (2017). Race and Gender Differences in Undergraduate Research Mentoring Structures and Research Outcomes. CBE Life Sci. Educ. 16 (2), 1-12. doi:10.1187/cbe.16-07-0211

Alston, G. D., Guy, B. S., and Campbell, C. D. (2017). Ready for the Professoriate? The Influence of Mentoring on Career Development for Black Male Graduate Students in STEM. J. Afr. Am. Males Educ. 8 (1), 45-66. 
Bahr, P. R., Jackson, G., McNaughtan, J., Oster, M., and Gross, J. (2017). Unrealized Potential: Community College Pathways to STEM Baccalaureate Degrees. J. Higher Educ. 88 (3), 430-478. doi:10.1080/00221546.2016.1257313

Baker, C. N. (2013). Social Support and success in Higher Education: The Influence of On-Campus Support on African American and Latino College Students. Urban Rev. 45, 632-650. doi:10.1007/s11256-013-0234-9

Banda, R. M., and Flowers, A. M. (2017). Birds of a Feather Do Not Always Flock Together: A Critical Analysis of Latina Engineers and Their Involvement in Student Organizations. J. Hispanic Higher Educ. 16, 359-374. doi:10.1177/ 1538192716662966

Beals, R. A. (2019). Transformative Education in Science, Technology, Engineering, and Mathematics: Empowering the Next Generation of Scientists. J. Hispanic Higher Educ. Online First. doi:10.1177/ 1538192719877414

Carpi, A., Ronan, D. M., Falconer, H. M., and Lents, N. H. (2017). Cultivating Minority Scientists: Undergraduate Research Increases Self-Efficacy and Career Ambitions for Underrepresented Students in STEM. J. Res. Sci. Teach. 54 (2), 169-194. doi:10.1002/tea.21341

Chemers, M. M., Zurbriggen, E. L., Syed, M., Goza, B. K., and Bearman, S. (2011). The Role of Efficacy and Identity in Science Career Commitment Among Underrepresented Minority Students. J. Soc. Issues 67, 469-491. doi:10.1111/ j.1540-4560.2011.01710.x

Clance, P. R., and Imes, S. A. (1987). The Imposter Phenomenon in High Achieving Women: Dynamics and Therapeutic Intervention. Psychotherapy: Theor. Res. Pract. 15 (3), 241-247. doi:10.1037/h0086006

Contreras, F. (2011). Strengthening the Bridge to Higher Education for Academically Promising Underrepresented Students. J. Adv. Academics 22 (3), 500-526. doi:10.1177/1932202X1102200306

Crisp, G., Reyes, N. A. S., and Doran, E. (2017). Predicting Successful Mathematics Remediation Among Latina/o Students. J. Hispanic Higher Educ. 16, 232-255. doi:10.1177/1538192715621950

Dika, S. L., and Martin, J. P. (2018). Bridge to Persistence: Interactions with Educators as Social Capital for Latina/o Engineering Majors. J. Hispanic Higher Educ. 17, 202-215. doi:10.1177/1538192717720264

Eagan, M. K., Stolzenberg, E. B., Zimmerman, H. B., Aragon, M. C., Whang Sayson, H., and Rios-Aguilar, C. (2017). The American Freshman: National Norms Fall 2016. Los Angeles: Higher Education Research Institute, University of California, Los Angeles.

Estepp, C. M., Velasco, J. G., Culbertson, A. L., and Conner, N. W. (2017). An Investigation into Mentoring Practices of Faculty Who Mentor Undergraduate Researchers at a Hispanic Serving Institution. J. Hispanic Higher Educ. 16, 338-358. doi:10.1177/1538192716661906

Estrada, M., Hernandez, P. R., and Schultz, P. W. (2018). A Longitudinal Study of How Quality Mentorship and Research Experience Integrate Underrepresented Minorities into STEM Careers. CBE Life Sci. Educ. 17 (ar9), 1-13. doi:10.1187/ cbe.17-04-0066

Fuchs, J., Kouyate, A., Kroboth, L., and Mcfarland, W. (2016). Growing the Pipeline of Diverse HIV Investigators: The Impact of Mentored Research Experiences to Engage Underrepresented Minority Students. AIDS Behav. 20 (1), 249-257. doi:10.1007/s10461-016-1392-z

Graham, B. E. (2019). Queerly Unequal: LGBT+ Students and Mentoring in Higher Education. Soc. Sci. 8 (6), 171-219. doi:10.3390/socsci8060171

Griffin, K. A., Pérez, D., II, Holmes, A. P. E., and Mayo, C. E. P. (2010). Investing in the Future: The Importance of Faculty Mentoring in the Development of Students of Color in STEM. New Dir. Institutional Res. 2010 (1), 95-103. doi:10.1002/ir.365

Hansson, L. (2018). "Science Education, Indoctrination, and the Hidden Curriculum," in History, Philosophy and Science Teaching: New Approaches. Editor M. Matthews (New York, NY: Springer), 283-306. doi:10.1007/978-3319-62616-1_11

Hezlett, S. A., and Gibson, S. K. (2007). Linking Mentoring and Social Capital: Implications for Career and Organization Development. Adv. Developing Hum. Resour. 9 (3), 384-411. doi:10.1177/1523422307304102

Hochanadel, A., and Finamore, D. (2015). Fixed and Growth Mindset in Education and How Grit Helps Students Persist in the Face of Adversity. J. Int. Educ. Res. 11 (1), 47-50. doi:10.19030/jier.v11i1.9099

Hurtado, S., Cabrera, N. L., Lin, M. H., Arellano, L., and Espinosa, L. L. (2009). Diversifying Science: Underrepresented Student Experiences in Structured
Research Programs. Res. High Educ. 50, 189-214. doi:10.1007/s11162-0089114-7

Hurtado, S., Gonzalez, R. A., and Galdeano, E. C. (2015). "Cross-Institutional Mentoring, Transformative Practice, and Collaboration Among HispanicServing Institutions," in Critical Approaches to the Study of Higher Education: A Practical Introduction. Editors A. M. Martinez-Aleman, B. Pusser, and E. M. Bensimon (Baltimore, MD: Johns Hopkins University), 177-195.

Jackson, M. C., Galvez, G., Landa, I., Buonora, P., and Thoman, D. B. (2016). Science that Matters: The Importance of a Cultural Connection in Underrepresented Students' Science Pursuit. CBE Life Sci. Educ. 15 (3), ar42. doi:10.1187/cbe.16-01-0067

Jensen, R. J., Petri, A. N., Day, A. D., Truman, K. Z., and Duffy, K. (2011). Perceptions of Self-Efficacy Among Stem Students with Disabilities. J. Postsecondary Educ. Disabil. 24 (4), 269-283.

Kendricks, K. D., Nedunri, K. V., and Arment, A. R. (2013). Minority Student Perceptions of the Impact of Mentoring to Enhance Academic Performance in STEM Disciplines. J. STEM Educ. Innov. Res. 14 (2), 38-46. Available at: https:// odi.osu.edu/uploads/Mentoring.pdf.

Kim, Y. K., and Sax, L. J. (2009). Student-Faculty Interaction in Research Universities: Differences by Student Gender, Race, Social Class, and FirstGeneration Status. Res. High Educ. 50 (5), 437-459. doi:10.1007/s11162-0099127-x

Kulturel-Konak, S., Konak, A., Esparragoza, I. E., and Kremer, G. E. O. (2013). "Assessing Professional Skills in STEM Disciplines," in 3rd IEEE Integrated STEM Education Conference, ISEC 2013, Princeton, NJ, March 9, 2013, 1-4. doi:10.1109/ISECon.2013.6525216

Leaper, C. (2014). Do I Belong?: Gender, Peer Groups, and STEM Achievement. Int. J. Gend. Sci. Technol. 7 (2), 166-179. Available at: http://genderandset.open. ac.uk/index.php/genderandset/article/view/405/672.

Malone, K. R., and Barabino, G. (2009). Narrations of Race in STEM Research Settings: Identity Formation and its Discontents. Sci. Ed. 93, 485-510. doi:10.1002/sce.20307

Meza, J. I., Rodriguez, K., Trujillo, C., and Ladd-Viti, C. (2018). Helping Students at the Margins Get into Graduate School: Evaluating a Multifaceted Mentoring Program. The Mentor: Innovative Scholarship Acad. Advising 20 (1), 26-41. doi:10.18113/P8mi2061075

Monarrez, A., Wagler, A., and Wagler, R. (2019). Latinx STEM Teacher Formation through a Cultural Wealth Lens. J. Hispanic Higher Educ. 20, 164-178. Advance Online Publication. doi:10.1177/1538192719835685

Mondisa, J.-L., and McComb, S. A. (2015). Social Community: A Mechanism to Explain the success of STEM Minority Mentoring Programs. Mentoring Tutoring: Partnership Learn. 23 (2), 149-163. doi:10.1080/ 13611267.2015.1049018

Mondisa, J.-L. (2020). The Role of Social Capital in African American STEM Mentoring Relationships. J. Women Minor. Scien Eng. 26 (2), 125-153. doi:10.1615/JWomenMinorScienEng.2020022267

Moschetti, R. V., Plunkett, S. W., Efrat, R., and Yomtov, D. (2017). Peer Mentoring as Social Capital for Latina/o College Students at a HispanicServing Institution. J. Hispanic Higher Educ. 17 (4), 375-392. doi:10.1177/ 1538192717702949

Museus, S. D., and Neville, K. M. (2012). Delineating the Ways that Key Institutional Agents Provide Racial Minority Students with Access to Social Capital in College. J. Coll. Student Develop. 53 (3), 436-452. doi:10.1353/ csd.2012.0042

Nevin, A., Smith, R. M., and McNeil, M. (2008). Shifting Attitudes of Related Service Providers: A Disability Study Critical Pedagogy Approach. Int. J. Whole Schooling 4 (1), 1-12. Gale Academic OneFile.

Pietri, E. S., Hennes, E. P., Dovidio, J. F., Brescoll, V. L., Bailey, A. H., MossRacusin, C. A., et al. (2018). Addressing Unintended Consequences of Gender Diversity Interventions on Women's Sense of Belonging in STEM. Sex Roles 80, 527-547. doi:10.1007/s11199-018-0952-2

Revelo, R. A., and Baber, L. D. (2018). Engineering Resistors: Engineering Latina/o Students and Emerging Resistant Capital. J. Hispanic Higher Educ. 17, 249-269. doi:10.1177/1538192717719132

Rist, R. (1970). Student Social Class and Teacher Expectations: The Self-Fulfilling Prophecy in Ghetto Education. Harv. Educ. Rev. 40 (3), 411-451. doi:10.17763/ haer.40.3.h0m026p670k618q3 
Robnett, R. (2012). The Role of Peer Support for Girls and Women in the STEM Pipeline: Implications for Identity and Anticipated Retention. Int. J. Gend. Sci. Technol. 5 (3), 232-253. Available at: http://genderandset.open.ac.uk/index. php/genderandset/article/download/299/521.

Rodriguez, S., Cunningham, K., and Jordan, A. (2019). STEM Identity Development for Latinas: The Role of Self- and Outside Recognition. J. Hispanic Higher Educ. 18, 254-272. doi:10.1177/1538192717739958

Royster, D. A. (2003). Race and the Invisible Hand: How white Networks Exclude Black Men from Blue-Collar Jobs. Oakland, CA: University of California Press. Available at: http://www.jstor.org/stable/10.1525/j.cttlpp42w.

Saw, G. K. (2020). Leveraging Social Capital to Broaden Participation in STEM. Pol. Insights Behav. Brain Sci. 7 (1), 35-43. doi:10.1177/2372732219895997

Schwartz, S. E. O., Kanchewa, S. S., Rhodes, J. E., Cutler, E., and Cunningham, J. L. (2016). "I Didn't Know You Could Just Ask:" Empowering Underrepresented College-Bound Students to Recruit Academic and Career Mentors. Child. Youth Serv. Rev. 64 (1), 51-59. doi:10.1016/j.childyouth.2016.03.001

Stanton-Salazar, R. D. (2011). A Social Capital Framework for the Study of Institutional Agents and Their Role in the Empowerment of Low-Status Students and Youth. Youth Soc. 43 (3), 1066-1109. doi:10.1177/0044118X10382877

Starobin, S. S., Smith, D. J., and Santos Laanan, F. (2016). Deconstructing the Transfer Student Capital: Intersect between Cultural and Social Capital Among Female Transfer Students in STEM fields. Community Coll. J. Res. Pract. 40 (12), 1040-1057. doi:10.1080/10668926.2016.1204964

Steele, C. M., and Aronson, J. (1995). Stereotype Threat and the Intellectual Test Performance of African Americans. J. Pers Soc. Psychol. 69, 797-811. doi:10.1037//0022-3514.69.5.797

Stolle-McAllister, K. (2011). The Case for Summer Bridge: Building Social and Cultural Capital for Talented Black STEM Students. Sci. Educator 20 (2), 12-22.

Tenenbaum, L. S., Anderson, M. K., Jett, M., and Yourick, D. L. (2014). An Innovative Near-Peer Mentoring Model for Undergraduate and Secondary Students: STEM Focus. Innov. High Educ. 39 (1), 375-385. doi:10.1007/s10755-014-9286-3
Wang, X. (2013). “Community College and Underrepresented Racial and Ethnic Minorities in STEM Education," in Community Colleges and STEM. Editors R. T. Palmer and J. L. Wood (New York, NY: Taylor \& Francis), 3-16.

Watkins, S. E., and Mensah, F. (2019). Peer Support and STEM success for One African American Female Engineer. J. Negro Educ. 88 (2), 181-193. doi:10.7709/jnegroeducation.88.2.0181

Wilson, Z. S., Holmes, L., deGravelles, K., Sylvain, M. R., Batiste, L., Johnson, M., et al. (2012). Hierarchical Mentoring: A Transformative Strategy for Improving Diversity and Retention in Undergraduate STEM Disciplines. J. Sci. Educ. Technol. 21 (1), 148-156. doi:10.1007/s10956-011-9292-5

Zaniewski, A. M., and Reinholz, D. (2016). Increasing STEM success: A Near-Peer Mentoring Program in the Physical Sciences. Int. J. STEM Educ. 3 (14), 1-12. doi:10.1186/s40594-016-0043-2

Conflict of Interest: The authors declare that the research was conducted in the absence of any commercial or financial relationships that could be construed as a potential conflict of interest.

Publisher's Note: All claims expressed in this article are solely those of the authors and do not necessarily represent those of their affiliated organizations, or those of the publisher, the editors and the reviewers. Any product that may be evaluated in this article, or claim that may be made by its manufacturer, is not guaranteed or endorsed by the publisher.

Copyright (c) 2021 Beals, Zimny, Lyons and Bobbitt. This is an open-access article distributed under the terms of the Creative Commons Attribution License (CC BY). The use, distribution or reproduction in other forums is permitted, provided the original author(s) and the copyright owner(s) are credited and that the original publication in this journal is cited, in accordance with accepted academic practice. No use, distribution or reproduction is permitted which does not comply with these terms. 